\title{
Os conjuntos-bairros \\ e a expansão do espaço \\ intraurbano de Fortaleza
}

\author{
Rérisson Máximo*
}

Resumo O Estado brasileiro atuou na questão habitacional de maneira diversa, com destaque para a produção direta, cujo resultado formal geralmente são conjuntos habitacionais. Construídos em diferentes momentos históricos, ganham significância com a atuação do Banco Nacional da Habitação, quando são construídos grandes conjuntos nas periferias urbanas. Por vezes compreendendo bairros inteiros, relacionam-se ao processo de desenvolvimento urbano e crescimento territorial das cidades. Este texto discute a expansão do espaço intraurbano e a produção habitacional na metrópole Fortaleza através da construção dos conjuntos-bairros, que apresentam sobreposição quase absoluta entre a área projetada e a divisão político-administrativa adotada pelas administrações municipais.

Palavras-chave: conjuntos-bairros, habitação, Fortaleza.

\section{Conjuntos-bairros and the expansion of intra-urban space in Fortaleza}

\begin{abstract}
The performance of Brazilian government regarding social housing took place in different ways, highlighting direct production which formal results are commonly housing projects. Built in different historical moments, they gain significance during the performance of National Housing Bank (BNH), when large housing estates are built in the urban peripheries. They cover sometimes whole neighborhoods and they are also linked to the process of urban development and territorial growth of main Brazilian cities. This paper presents and discusses the expansion of intra-urban space and housing production in Fortaleza through the construction of conjuntos-bairros, which present almost absolute overlap among projected area and administrative division adopted by local administrations.
\end{abstract}

Keywords: conjuntos-bairros, housing, Fortaleza.

\section{Los conjuntos-barrios y la expansión del espacio intraurbano en Fortaleza}

Resumen El Estado brasileño actuó con relación a la cuestión habitacional de diversas maneras, destacándose la producción directa, cuyo resultado formal generalmente son conjuntos habitacionales. Construidos en diferentes momentos históricos, ganan significado con la actuación del Banco Nacional de la Habitación, cuando son construidos grandes conjuntos en las periferias urbanas. A veces comprendiendo barrios enteros, se relacionan al proceso de desarrollo urbano y crecimiento territorial de las ciudades. Este texto discute la expansión del espacio intraurbano y la producción habitacional en la metrópolis Fortaleza, a través de la construcción de los conjuntos-barrios, que presentan sobre posición casi absoluta entre el área proyectada y la división político-administrativa adoptada por las administraciones municipales.

Palabras clave: conjuntos-barrios, habitación, Fortaleza. 
A

lógica da produção em massa de moradias deu a tônica da política urbana e habitacional e, por consequência, do que foi produzido durante a atuação do Banco Nacional da Habitação (BNH), principal órgão do então Sistema Financeiro da Habitação (SFH) e que funcionou mais como produtor de habitação do que como agente financeiro. Essa atuação resultou na mais significativa produção de moradias no país, por meio de inúmeros e imensos conjuntos habitacionais localizados nas periferias urbanas - por vezes compreendendo bairros inteiros - e que diretamente se relacionam à maneira como se deu o processo de desenvolvimento urbano e crescimento territorial nas metrópoles brasileiras. Ainda que o BNH tenha atuado produzindo habitação de diferentes maneiras, são os grandes conjuntos que melhor representam a lógica presente naquele momento da política urbana e habitacional no Brasil.

Desta política de produção em massa restaram críticas sobre a forma como aqueles empreendimentos foram construídos, sobretudo por parte de autores que tratam da questão urbana e habitacional, como a feita por Comas (1983). Levanta-se, geralmente, como características de tal produção habitacional: a exclusão da urbanidade, a ausência de qualidade projetual e construtiva e a redução do tema a uma questão numérica, já que importava a quantidade, a área e o custo das moradias (Rubano, 2001). Critica-se geralmente ainda a maneira como se deu a implementação destas ações habitacionais, distante do ideário da reforma urbana e com acesso à moradia dado exclusivamente pela propriedade privada.

Mesmo que se tratando de um contexto municipal específico, apresentamos neste texto um caso paradigmático como o de Fortaleza para compreender as relações entre o processo de expansão do seu espaço intraurbano (Villaça, 2001) e a produção habitacional do BNH na capital cearense, através da construção dos chamados conjuntosbairros, núcleos habitacionais de grande porte que apresentam como característica fundamental a sobreposição quase que absoluta entre a área projetada e a divisão político-administrativa adotada pelas administrações municipais.

Em Fortaleza, estes grandes conjuntos, construídos ao longo das décadas de 1970 e 1980, induziram à expansão periférica do território da metrópole, levando a processos de conurbação entre Fortaleza e alguns municípios como Caucaia e Maracanaú. Mais ainda, tais conjuntos, pensados para abrigar a massa de trabalhadores, acabaram virando sinônimo de baixa qualidade projetual e construtiva, características ainda bastante presentes nos recentes projetos de habitação social desenvolvidos em Fortaleza. São algumas destas questões que buscaremos tratar a seguir.

* Rérisson Máximo é Arquiteto e Urbanista, professor do Instituto Federal do Ceará. ORCID $<$ https://orcid.org/0000-00031340-8390>

\section{Algumas questões gerais sobre a política habitacional do BNH}

O Banco Nacional da Habitação (BNH) marcou uma nova fase da política habitacional federal. Criado pelo regime militar, teve como objetivo central estruturar um sistema de 
crédito habitacional, através do FGTS, que se constituiu como uma fonte de recursos permanente de financiamento da produção de moradias. Pretendia-se minimizar os investimentos subsidiados e impedir uma descapitalização do sistema. Devido a gestão centralizada, característica do SFH, raras foram as realizações de governos municipais ou estaduais na área de habitação, tal a concentração de recursos e decisões junto ao governo federal durante o período de atuação do banco (Maricato, 1987).

O modelo praticado era baseado no financiamento às construtoras e não ao usuário final. Dessa forma, buscava-se a queda do custo da unidade habitacional, mas também do empreendimento como um todo, não apenas como forma de enquadrar o empreendimento ao público-alvo ao qual o BNH buscava atender, mas também para elevar ao máximo possível os lucros. Diante dessa lógica, como aponta Bonduki (2013), a partir da década de 1960, decorre uma separação entre arquitetura e moradia popular, com graves repercussões na qualidade do espaço construído.

Dentre os fatores relacionados à realidade apresentada pelas grandes cidades brasileiras, geralmente aponta-se a insuficiente atuação do Estado ou a atuação desregulada do setor privado, via-de-regra associado a interesses especulativos. Destaca-se ainda a maneira informal que os trabalhadores autoconstroem suas casas, principalmente em favelas e loteamentos irregulares ou clandestinos. Contudo, há de se ressaltar que o poder público, durante o período de atuação do BNH, produziu - seja através da regulação, do financiamento ou da construção - uma quantidade extremamente significativa do espaço urbano brasileiro que, se contrariado a lógica então em voga, poderia apresentar uma maior qualidade espacial.

Ainda que na primeira metade do século tenham sido observadas experiências positivas na arquitetura habitacional produzida sob a tutela do Estado (Rubano, 2001), a produção do BNH foi caracterizada pelo abandono destas experiências em troca da construção de conjuntos habitacionais de grande porte e implantados em áreas periféricas, através da padronização dos componentes e espaços. Mesmo contando com unidades habitacionais de áreas superiores às recentemente produzidas, além de razoável oferta de infraestrutura, serviços e equipamentos sociais (Pequeno \& Aragão, 2009); os conjuntos habitacionais construídos à época do BNH, pensados para abrigar a população de trabalhadores dos setores industrial e terciário, acabaram virando sinônimo de baixa qualidade projetual e construtiva e favoreceram a construção ideológica de uma forma de produzir moradias que caracteriza o chamado padrão-BNH, que ainda exerce forte influência nos recentes projetos de habitação social.

Caracteriza-se o chamado padrão-BNH (Comas, 1983) pelos projetos de grandes dimensões, muitas vezes constituindo bairros inteiros; a precária ou mesmo inexistente interligação à malha urbana, já que geralmente se localizavam em áreas periféricas, haja vista o menor custo da gleba a ser desapropriada; pela baixa qualidade projetual e construtiva das unidades habitacionais; pela padronização das tipologias utilizadas; e ainda pelo abandono das áreas inicialmente pensadas para abrigar os espaços coletivos e institucionais. Tudo isso contribuiu para a produção de núcleos habitacionais que induziram a expansão urbana desordenada e que ofereciam péssimas condições de habitabilidade, resultante tanto das próprias características do meio urbano onde foram inseridos quanto da intencional redução de custos. 
1 Outros importantes elementos que poderiam ser destacados, dentro do processo de estruturação do espaço intraurbano de Fortaleza são os edifícios institucionais da administração pública, com destaque para o Centro Administrativo Virgílio Távora, sede de muitos órgãos do governo estadual; e equipamentos privados de grande porte como o Shopping Iguatemi e a Universidade de Fortaleza. Contudo, destacamos aqueles que mais se relacionam às questões tratadas diretamente por este texto.

2 Inserida no mesmo processo de institucionalização das outras regiões metropolitanas, quando o Estado se propõe a dispor sobre o espaço urbano através de uma ação planejadora, a RMF é instituída pela Lei Complementar № 14, de 8 de junho de 1973.

\section{Estruturação do espaço intraurbano de Fortaleza}

No que se refere à estruturação do espaço intraurbano de Fortaleza, podem ser destacados três elementos principais que, de forma conjunta, ainda que não necessariamente integrados, possibilitaram a conformação do que hoje se apresenta como a Região Metropolitana de Fortaleza: os espaços destinados à produção industrial, o sistema viário principal e os núcleos habitacionais construídos pelo poder público sob a forma de grandes conjuntos. A expansão territorial alcançada durante o processo de estruturação daquele espaço é, em grande parte, resultado direto da atuação do Estado em torno destes três elementos ${ }^{1}$.

Como bem aponta Gondim (1987), "o processo histórico de formação da estrutura urbana de Fortaleza evidencia a atuação do Estado como agente político e econômico da produção do espaço urbano, no contexto de um capitalismo periférico dominado pelos interesses de grupos comerciais e agrários". Em outras palavras, Accioly (2009) também reforça o papel do Estado nesse processo, ao argumentar que "as políticas públicas, desde a década de 1970 e 1980, propiciaram a construção de rodovias, a melhoria do sistema de transporte, a implantação de projetos turísticos, industriais e conjuntos habitacionais, financiados pelo Estado".

Vale ser ressaltado que, num primeiro momento, o avanço dos limites do que era então considerado como espaço urbano da metrópole cearense se deu em consequência, sobretudo, do fluxo migratório campo-cidade, verificado principalmente até a década de 1940, momento quando começam a se constituir as primeiras favelas e que passaram a abrigar parcela expressiva da população migrante (Jucá, 2003; Costa, 2005). Dessa maneira, até o final dos anos 1950 e início da década seguinte, o lugar da habitação para a classe trabalhadora foi sendo definido de maneira relativamente dispersa ao longo do território da cidade. Apesar de haver um destaque da zona oeste de Fortaleza pela predominância de um proletariado em crescimento, de certa forma associado aos equipamentos industriais tradicionalmente implantados naquele trecho da cidade, diversas outras áreas iam sendo ocupadas por assentamentos populares.

Fortaleza, sendo o centro urbano concentrador dos investimentos e de capitais, do aparelho burocrático estadual e também dos principais fluxos migratórios; seguia as mesmas determinações que o Estado brasileiro assumira naquele momento: fortalecer o setor produtivo, normalmente sem se preocupar com as condições de reprodução da força de trabalho, que se concentrava nos grandes centros urbanos. Tal preocupação, de certa forma vai aparecer somente no final da década de 1960 e início dos anos 1970, quando são institucionalizadas as regiões metropolitanas brasileiras, dentre elas a de Fortaleza; e quando são elaborados um conjunto de planos territoriais, já como ação de planejamento adotada dentro do Sistema Financeiro da Habitação, através do SERFHAU ${ }^{2}$.

Como resultado desta ação planejadora do Estado, em 1972 é elaborado o Plano de Desenvolvimento Integrado da Região Metropolitana de Fortaleza (Plandirf). A partir do diagnóstico elaborado por este plano, propôs-se a integração regional mediante diretrizes segundo as quais o Estado buscaria resolver os problemas identificados através de políticas consideradas fundamentais: "política de emprego, renda e migração; política agropecuária regional; política viária e política habitacional" (Fortaleza, 1972, grifo nosso). O plano previa, entre outros aspectos, a redução das disparidades urbano- 
regionais, com o objetivo de descentralizar os fluxos migratórios concentrados em Fortaleza. Contudo é a política habitacional que fornecerá elementos para entender porque e como a periferia de Fortaleza foi se constituindo, predominada em algumas áreas por conjuntos habitacionais de grande porte que configuraram naquele momento, ou posteriormente, verdadeiros bairros que, em alguns casos, se apresentavam populacionalmente maiores que cidades do interior do Ceará.

A política de produção de habitações na periferia não era particularidade de Fortaleza. Ela era posta em prática por todo o país, tendo como suporte o SFH e o BNH, no âmbito federal, e as companhias de habitação, no âmbito estadual. O que não foi por acaso, mas fruto do processo de reprodução social pelo qual o país estava atravessando, quando se punha como exigência que o Estado atuasse nos espaços urbanos de forma mais sistemática, no sentido de

"viabilizar e garantir para a classe trabalhadora e do proletariado em crescimento a reprodução das condições de vida nas cidades, o que, em última instância, significava a redefinição dos espaços urbanos por conta dos novos patamares alcançados pela acumulação capitalista" (Martins, 1995).

A necessidade, portanto, de uma política voltada para o espaço urbano tem na política habitacional uma de suas âncoras. Escolhida como parte central para o desenvolvimento urbano da década de 1970, a questão habitacional foi encarada como fundamental diante do processo de urbanização que o país alcançava. Trazia-se para a discussão a problemática da habitação que se tornava emergente. Tal problemática adquire relevância à medida que a expansão das periferias, carentes dos serviços de infraestrutura urbana, tornava-se a tônica da urbanização no país.

Nesse processo de estruturação da Região Metropolitana de Fortaleza, cujo pano de fundo é dado pelos diagnósticos elaborados pelo Plandirf, a política habitacional teve inegável destaque, uma vez que não apenas estava submetida à política de desenvolvimento metropolitano, como constituíra-se num dos pilares fundamentais da reorganização espacial de Fortaleza. O Plandirf colocava, como diretrizes: a definição e expansão da área urbana; a hierarquização da rede viária básica, a partir do seu traçado e seu dimensionamento; formalização do uso do solo urbano, explicitando os zoneamentos, identificando os aspectos de localização, dimensão e caracterização das áreas de diferentes usos (Fortaleza, 1972).

A organização espacial metropolitana prevê, portanto, programas no sentido de viabilizar a funcionalidade e a integração do desenvolvimento urbano. É neste momento que são planejados para Fortaleza os chamados corredores de adensamento. Num primeiro momento foram construídos corredores viários como as avenidas José Bastos, Osório de Paiva, João Pessoa e Aguanambi - todas seguindo a orientação centrobairro -, que tinham como objetivo viabilizar a integração das áreas periféricas à área central. Posteriormente, deu-se a implantação do corredor da Avenida Bezerra de Meneses, principal saída para a BR-222, e que se constituiu em um dos importantes eixos viários que, além de melhorar a ligação com o município de Caucaia, também conectava um setor com grande concentração de conjuntos habitacionais. Destaca-se ainda a construção da Avenida Leste Oeste como importante eixo viário de ligação entre a zona industrial, à oeste, e a zona portuária, à leste. É a esses projetos de 
construção de novas vias, ou de ampliação ou remodelação daquelas existentes, que os programas de desfavelamento em Fortaleza são justificados pelo poder público municipal como de fundamental importância.

\section{As ações de desfavelamento em Fortaleza}

Em meados do século XX, Fortaleza apresentava, distribuídos ao longo de seu território, inúmeros aglomerados habitacionais ocupados por população de baixa renda. Estes núcleos estavam localizados principalmente ao longo da faixa litorânea, em áreas de encostas de dunas, em faixas de reserva, próximas à rede ferroviária, em áreas marginais aos principais rios da cidade (Cocó e Maranguapinho) e, em alguns casos, em leitos de vias (Castro, Guedes \& Britto, 1972).

No início dos anos 1960, diante da situação de precariedade habitacional, a administração municipal, através da Fundação de Serviço Social de Fortaleza (FSSF), começa a desenvolver projetos e estudos de planejamento e de assistência social para a população de baixa renda, que resultam em ações de desfavelamento - termo utilizado na época - das áreas centrais da cidade. Tais programas, de acordo com os documentos oficiais publicados pela própria prefeitura (Fortaleza, 1973), tinham metas bastantes ambiciosas: remoção dos núcleos favelados existentes na época que abrigavam 63 mil moradias e uma população de 223 mil habitantes (Castro, Guedes \& Britto, 1972).

Os primeiros programas de desfavelamento, conduzidos pela FSSF e traduzidos no reassentamento das famílias em outras áreas através de conjuntos habitacionais, datam do final da década de 1960. Tais programas, nesse primeiro momento, estão associados à abertura ou urbanização de importantes vias da capital cearense ou à implantação de equipamentos urbanos. Marco inicial da atuação da FSSF na promoção de habitação é a construção, em 1966, do Conjunto Habitacional Santa Luzia do Cocó. Contudo, o exemplo inicial do que seria a tônica do programa de desfavelamento é a intervenção na Favela do Trilho, situada próxima à avenida Borges de Melo, sendo a primeira favela removida pela Fundação de Serviço Social de Fortaleza.

A remoção desta favela se deu para a construção do Terminal Rodoviário de Fortaleza e a urbanização de sua principal via de acesso (Cetrede, 1981). Das 313 famílias que ocupavam esta favela, 121 foram transferidas para o Conjunto Alvorada, localizado no setor centro-leste da cidade. Chamado de conjunto habitacional, o Alvorada consistia num programa de reassentamento através de lotes urbanos financiados pela FSSF (Braga \& Barreira, 1991). Em 1972, é iniciada a retirada de outras favelas em áreas centrais de Fortaleza, como aquelas situadas na Avenida Estados Unidos (atual Virgílio Távora), na Avenida Senador Machado e no Alto da Piçarra. Parte das famílias que ocupavam esses núcleos habitacionais também foram transferidas para o Conjunto Alvorada. Já o projeto de construção da Avenida Leste-Oeste, ligando a zona portuária do Mucuripe à zona industrial da Barra do Ceará - os dois limites extremos ao norte da capital cearense -, levou à remoção de outras favelas que estavam localizadas ao longo do trecho da avenida, como parte do bairro Pirambu e Arraial Moura Brasil, próximo à zona central de Fortaleza.

Grande parte da população moradora desses núcleos foram reassentadas no Conjunto Marechal Rondon, localizado distante do centro da capital, já nos limites do município 
de Caucaia, integrante da Região Metropolitana. Percebe-se que as famílias que ocupavam essas áreas de renovação urbana foram transferidas para locais distantes dos centros de emprego e precariamente equipados. Tal deslocamento não só afetou as oportunidades de trabalho como acarretou aumento do custo e tempo consumido em transporte. O caso do conjunto Marechal Rondon, situado no limite com Caucaia, parece ser emblemático do processo que depois vai ser a lógica da política habitacional em Fortaleza, e que também ocorreu em outros centros urbanos brasileiros: a ocupação da periferia através de grandes conjuntos habitacionais.

Diante do agravamento do problema habitacional em Fortaleza, sobretudo a partir das décadas de 1960 e 1970, e por meio destas primeiras ações de desfavelamento implementadas pela FSSF, o poder público municipal elabora um programa orientado para a intervenção no conjunto de favelas e assentamentos precários que existiam distribuídos ao longo do território da capital cearense. O chamado Programa Integrado de Desfavelamento da Cidade de Fortaleza constituía-se como importante instrumento político que, associado à outras ações, orientou algumas das principais ações habitacionais em Fortaleza, nas décadas de 1970 e 1980 (Fortaleza, 1973).

O Programa Integrado de Desfavelamento apresentava dois principais objetivos. Primeiro, propõe "projetos de desfavelamento, através de 'ação corretiva' das zonas marginais, quando se evidencia como necessária a remoção de seus ocupantes" (Fortaleza, 1973). Segundo, estabelece "medidas de ação preventiva, ou seja, de recuperação dos núcleos cuja erradicação não será necessária e que, inclusive, apresentam alto potencial de renovação urbana" (Fortaleza, 1973). Na verdade, estas ações de desfavelamento estão associadas diretamente a outro conjunto de intervenções urbanas na cidade, sobretudo no que se refere à reestruturação viária a partir do alargamento ou criação de novos eixos de circulação de veículos, como já foi exposto anteriormente. O programa é orientado a partir da experiência adquirida nos dois projetos já desenvolvidos: os conjuntos Alvorada e Marechal Rondon.

Conforme o Estudo Preliminar do Programa, as populações removidas seriam

"orientadas através de um plano urbanístico operacional, a ocupar outras áreas da cidade, onde deverão ser implantados projetos de nucleamentos para desfavelados, que se integrem no crescimento de Fortaleza, quanto a suas condições sociais e econômicas, semelhantes aos atuais projetos experimentais - Marechal Rondon e Alvorada" (Fortaleza, 1973).

Segundo o mesmo documento, a intenção de tal política seria, tendo como público-alvo as populações marginalizadas, "integrá-las, gradativamente, ao processo de urbanização, de maneira a oferecer-Ihes condições de utilizarem, também, os benefícios oferecidos pelo progresso da cidade". Na prática, não foi isso o que realmente aconteceu, pelo menos com aquelas favelas que foram removidas e sua população reassentada nos conjuntos habitacionais construídos na periferia.

Ainda que se tratando de um estudo preliminar, o documento que apresenta o Programa de Desfavelamento aponta, através de mapas, informações importantes sobre a problemática habitacional em Fortaleza. Primeiramente, espacializa todos os 83 núcleos de favelas, ou assentamentos subnormais, então existentes na 
Figura 1: Mapa de localização das favelas em Fortaleza no ano de 1973. Fonte: Fortaleza (1973). cidade (ver Figura 1). Depois, destaca e espacializa os núcleos selecionados como prioritários para o desfavelamento. Por último, aponta algumas áreas nas quais os projetos de desfavelamento seriam desenvolvidos (ver Figura 2). São estas áreas, identificadas como locais para abrigar a população desfavelada, que serão utilizadas para a construção dos grandes conjuntos habitacionais.

Com o passar do tempo, os moradores de algumas das favelas alvos de intervenção dentro do programa de desfavelamento, beneficiando-se de uma conjuntura política mais favorável, passam a buscar a permanência no local, como aconteceu com a favela da José Bastos, no final da década de 1970. Apesar de derrotados, é provável que a sua resistência tenha sido um dos fatores que levou o governo a modificar a sua política habitacional, criando em 1979 um órgão voltado principalmente para a urbanização de favelas, a Fundação Programa de Assistência às Favelas da Região Metropolitana de Fortaleza (Proafa). Dentre seus programas, destaca-se a urbanização das favelas do Lagamar e de Santa Teresinha, onde se deu a construção de conjuntos habitacionais, também de porte significativo (Braga \& Barreira, 1991).

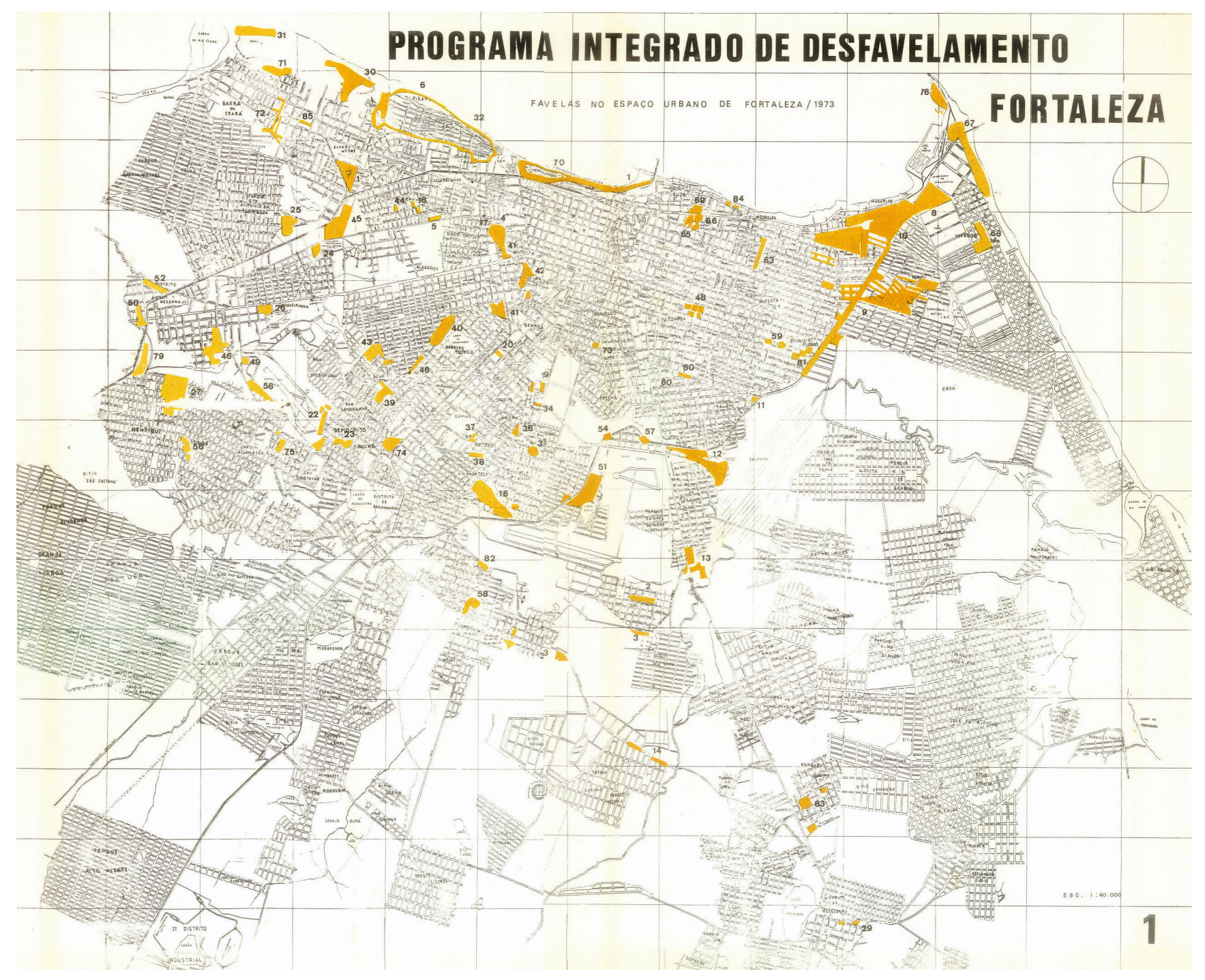




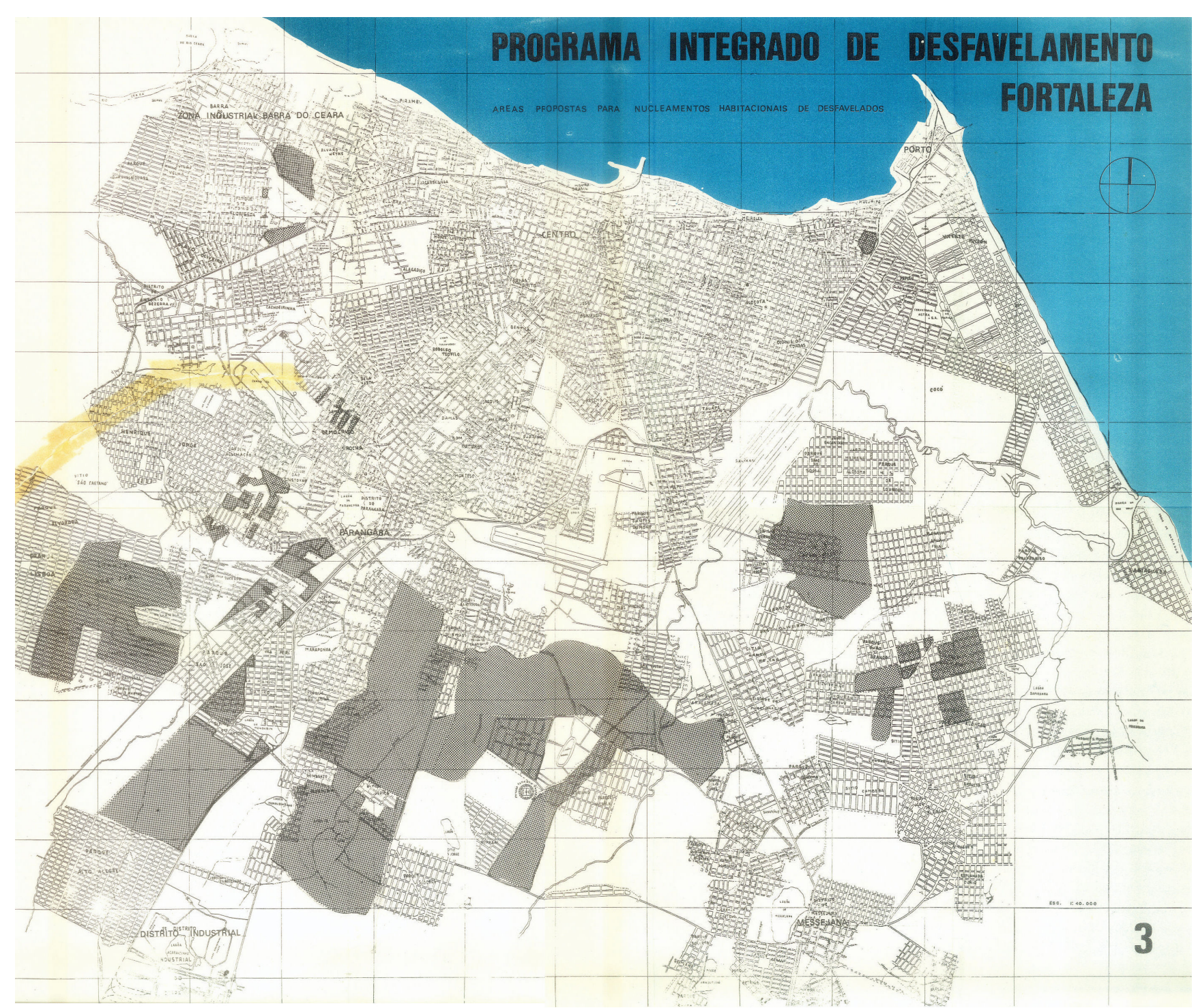

Figura 2: Mapa das áreas propostas para os Nucleamentos Habitacionais de Desfavelados. Fonte: Fortaleza (1973).

\section{Os conjuntos-bairros}

"Política de desenvolvimento urbano como a criação de instrumentos e meios de atuação estratégica para se lograr, no menor espaço de tempo e com custos mais reduzidos, a estruturação regional e das cidades [...], visando à incorporação de maior contingente populacional aos benefícios da urbanização" (Fortaleza, 1973).

O trecho anterior expõe, de certa forma, a visão da política habitacional praticada em Fortaleza, assim como em sua região metropolitana, nas décadas de 1970 e 1980 . A 'incorporação de maior contingente populacional aos benefícios da urbanização' era posta como principal diretriz no atendimento às demandas habitacionais decorrentes, sobretudo, do rápido incremento populacional que acontecia na capital e nos municípios vizinhos. É essa racionalidade da produção em massa de moradia que vai dar suporte à construção dos grandes conjuntos periféricos. 
3 Os conjuntos construídos pela FSSF foram: Alvorada (1971) com 310 unidades habitacionais; Marechal Rondon (1972) com 1280 moradias; e o Palmeiras (1974) com 732 unidades habitacionais (Ceará, 1978).

Quadro 1: Maiores conjuntos habitacionais construídos na RMF pelo $\mathrm{BNH}$.

(*) Conjuntos construídos em diferentes etapas, identificando datas de entrega da primeira e última.

(**) Informações aproximadas, conforme Costa (1988).

Fonte: Autor (2012) adaptado de Mesquita et al. (2000).
Em Fortaleza, a atuação do poder público no setor habitacional está representada, num primeiro momento, pelas obras realizadas pela FSSF. No período entre os anos de $1969 \mathrm{e}$ 1978, esta Fundação construiu três conjuntos habitacionais, totalizando 2322 unidades habitacionais ${ }^{3}$. Como já foi visto anteriormente, esta produção estava associada diretamente aos programas de desfavelamento que eram postos em prática pelo poder público local. Ainda que os conjuntos resultantes destas ações apresentassem um menor número de unidades por empreendimento ou mesmo a localização nos próprios locais das favelas que eram reassentadas, havia um indicativo da lógica de produção em grandes quantidades e da localização periférica, como aconteceu com Conjunto Marechal Rondon, implantado no limite sudoeste de Fortaleza, já próximo do município de Caucaia.

Nesse período, contudo, a construção dos grandes conjuntos habitacionais para a população de baixa renda - não necessariamente proveniente das favelas existentes na cidade - foi executada principalmente pela $\mathrm{COHAB}-\mathrm{CE}$, órgão estadual e agente vinculado ao SFH e ao BNH. A dimensão dessa produção habitacional pode ser observada se tomarmos a quantidade de unidades habitacionais dos onze maiores conjuntos. Esse número corresponde a mais de quarenta mil domicílios. Fazendo-se uma estimativa pelo índice médio de ocupação por domicílio, que na época era de seis moradores, chegaremos ao valor equivalente a um quinto da população total de Fortaleza no ano de 1980 (Autor, 2012).

São exatamente estes onze grandes núcleos habitacionais que trataremos neste texto como conjuntos-bairros. Além das características já apresentadas para os grandes conjuntos habitacionais produzidos pelo Banco Nacional da Habitação, os conjuntos-bairros apresentam, como aspecto que os distinguem, a sobreposição quase que absoluta entre a área projetada e a divisão político-administrativa adotada pelas administrações municipais atualmente. Sobre este aspecto, em seu estudo sobre o processo de desenvolvimento e degradação do espaço urbano em Fortaleza, Pequeno (2002) já apontava estes conjuntos habitacionais como uma das categorias de tecido urbano presentes da cidade. Destacam-se ainda a disponibilidade de infraestrutura de saneamento ambiental e de equipamentos sociais como elementos que caracterizam esses núcleos habitacionais enquanto conjuntos-bairros.

\begin{tabular}{|l|l|l|l|}
\hline CONJUNTO & MUNICíPIO & $\begin{array}{l}\text { UNIDADES } \\
\text { HABITACIONAIS }\end{array}$ & CONCLUSÃo \\
\hline José Walter & Fortaleza & 4774 & $1969-1973^{*}$ \\
\hline Cidade 2000 & Fortaleza & $2000^{* *}$ & 1971 ** \\
\hline Ceará & Fortaleza & 8669 & $1977-1981^{*}$ \\
\hline Industrial & Maracanaú & 1276 & 1979 \\
\hline Esperança & Fortaleza & 2039 & 1981 \\
\hline Acaracuzinho & Maracanaú & 1976 & 1982 \\
\hline Timbó & Maracanaú & 2900 & 1983 \\
\hline Jereissati & Maracanaú & 11334 & $1984-1987 *$ \\
\hline Planalto Caucaia & Caucaia & 1264 & 1984 \\
\hline Araturi & Caucaia & 2230 & 1985 \\
\hline Nova Metrópole & Caucaia & 5537 & $1985-1989 *$ \\
\hline
\end{tabular}


Afora a capital cearense, os municípios da Região Metropolitana de Fortaleza nos quais se concentram o maior número de conjuntos habitacionais são Caucaia e Maracanaú, justamente aqueles escolhidos para a implantação de distritos industriais naquele momento. Os grandes conjuntos, construídos para abrigar os trabalhadores que ocupariam as áreas industriais, mas também do setor terciário, foram dispostos estrategicamente nas proximidades desses distritos, bem como próximos às linhas férreas. Estes dois elementos presentes na estrutura do espaço intraurbano de Fortaleza - os distritos industriais e a rede ferroviária - vão orientar a localização dos conjuntos-bairros.

A partir da década de 1960, ocorre um processo de expansão do espaço intraurbano de Fortaleza, quando começa a ocupação de bairros mais afastados do centro da capital, localizados notadamente no quadrante sudoeste; e de loteamentos periféricos localizados em Antônio Bezerra, Mondubim, Messejana e parte de Caucaia, entre os rios Maranguapinho e Ceará (Gondim, 1987). Contudo, é a localização destes conjuntosbairros, orientada pelos elementos anteriormente citados, que se constitui como fator importante para a consolidação da expansão periférica de Fortaleza e crescimento territorial dos municípios de Caucaia e Maracanaú, integrantes da Região Metropolitana. Isto pode ser observado como diretriz apontada nos próprios documentos oficiais. O Plandirf coloca que:

"A atual estrutura radiocêntrica de Fortaleza, já bastante comprometida no centro da trama urbana, é contraindicada para a localização de conjuntos habitacionais, sendo recomendável a sua localização na vizinhança dos principais eixos viários de ligação da cidade com sua região de influência. Em decorrência, indica-se prioritariamente que os terrenos a serem adquiridos pela COHAB e COHTRACE estejam situados nos eixos que constituem o sistema de trânsito rápido, principalmente em direção a Caucaia e Maracanaú" (Fortaleza, 1972, p.210).

O conjunto José Walter, construído no distrito de Mondubim e tendo sido entregue, sua última etapa, em 1973, pode ser considerado o primeiro conjunto-bairro implantado em Fortaleza. Inicialmente foi chamado de Núcleo Habitacional Integrado, justamente pelas suas características - disponibilidade de equipamentos sociais e infraestrutura urbana que ofereciam um certo grau de independência, mais do entorno imediato que da cidade como um todo. O Conjunto José Walter contribuiu para o crescimento vertiginoso daquele distrito, cuja população quase triplicou entre os anos de 1970 e 1980, passando de 66.618 para 192.945 habitantes (Gondim, 1987). A localização de conjuntos habitacionais também contribuiu para o crescimento populacional dos municípios da periferia metropolitana. Nesse período, a população de Maracanaú mais do que duplicou, passando de 15.685 em 1970 para 37.834 habitantes em 1980, e a de Caucaia apresentou um crescimento de $72 \%$ na mesma década, aumentando de 54.754 para 84.108 habitantes (Gondim, 1987).

Em Fortaleza, os conjuntos foram distribuídos espacialmente na periferia, ocupando grandes glebas onde o valor da terra era menor. A implantação destes conjuntos habitacionais de grande porte como o Conjunto Ceará, localizado no setor sudoeste da cidade, propiciou a conurbação com Caucaia, município onde também foram implantados outros grandes conjuntos, como o Araturi, Planalto Caucaia e Nova Metrópole. Na parte sul de Fortaleza, em grande trecho de seu setor periurbano, outros grandes conjuntos habitacionais, como o Esperança e o José Walter, proporcionaram a integração da malha 
urbana entre Fortaleza e Maracanaú. Neste município, os conjuntos foram localizados sobretudo no entorno do seu distrito industrial. Destacam-se os conjuntos Industrial, Jereissati, Acaracuzinho e Timbó.

Segundo Pequeno (2002), estes conjuntos apresentam inclusive uma clara diferença nos padrões socioambientais em relação aos bairros vizinhos devido à implantação de redes de infraestrutura urbana, condição que difere dos loteamentos periféricos que vieram a complementar o tecido urbano entre os dois municípios. De acordo com aquele autor, foram construídos grandes conjuntos habitacionais nos municípios de Caucaia, Maracanaú e Pacatuba, em áreas periféricas e não urbanizadas, resultando em pressões sobre o poder público local para implantação de redes de infraestrutura, equipamentos sociais e transportes, induzindo a expansão territorial de Fortaleza na direção oeste e sudoeste (Pequeno, 2002).

A seguir, apresentaremos algumas características gerais de alguns dos conjuntos-bairros construídos na Região Metropolitana de Fortaleza: os conjuntos José Walter, Esperança, Ceará e Nova Metrópole. Existem outros conjuntos que apresentam características que também os distinguem como conjuntos-bairros, mas que não serão abordados neste texto, como é o caso do Cidade 2000, em Fortaleza; Industrial, Acaracuzinho, Jereissati e Timbó, em Maracanaú; e Planalto Caucaia e Araturi, em Caucaia.

O conjunto José Walter, como já exposto anteriormente, pode ser considerado o primeiro conjunto-bairro construído no espaço intraurbano de Fortaleza. Está localizado ao sul da cidade, às margens do então Terceiro Anel Viário, ramal rodoviário transformado em Avenida Perimetral, a partir da expansão territorial da capital cearense. Esta localização é, inclusive, emblemática da lógica de periferização então adotada na implantação destes projetos habitacionais. Foram construídas 4774 unidades habitacionais, entregues em quatro etapas, entre os anos de 1969 e 1974. Por conta dessa grande quantidade de moradias, na época da sua inauguração foi considerado um dos maiores conjuntos habitacionais da América Latina. Além das unidades habitacionais, inseridas em lotes de mesma dimensão e variações tipológicas associadas apenas ao número de dormitórios, o projeto do conjunto contemplava equipamentos sociais tais como: escolas, banco, posto de saúde, clube social, delegacia, centros comerciais, igreja, praças de esporte, centro cívico, cinema, bosque e teatro de arena. Alguns destes equipamentos foram construídos apenas após a entrega das casas e outros ficaram apenas no projeto. Atualmente, o José Walter é um dos bairros oficiais de Fortaleza.

Localizado também na parte sul de Fortaleza, o conjunto habitacional Esperança é outro conjunto-bairro. Foram construídas 2039 unidades habitacionais, entregues em etapa única, no ano de 1981. Além das habitações, foram construídos alguns importantes equipamentos como escolas - quatro no total, que inclusive passaram a atender a demanda dos moradores dos loteamentos adjacentes ao conjunto --, centros comerciais, posto de saúde, delegacia policial e instalações esportivas, como quadra e campo de futebol. Estes equipamentos localizam-se numa espécie de centro de bairro, dividindo as duas áreas com predominância do uso residencial. Estas áreas têm características bem distintas definidas pela tipologia habitacional: uma parte composta por blocos residenciais multifamiliares de dois pavimentos e outra compreendida por unidades habitacionais térreas, unifamiliares e isoladas no lote. O Esperança, apesar menor em extensão que outros conjuntos-bairros também é oficialmente uma unidade administrativa da prefeitura de Fortaleza. 

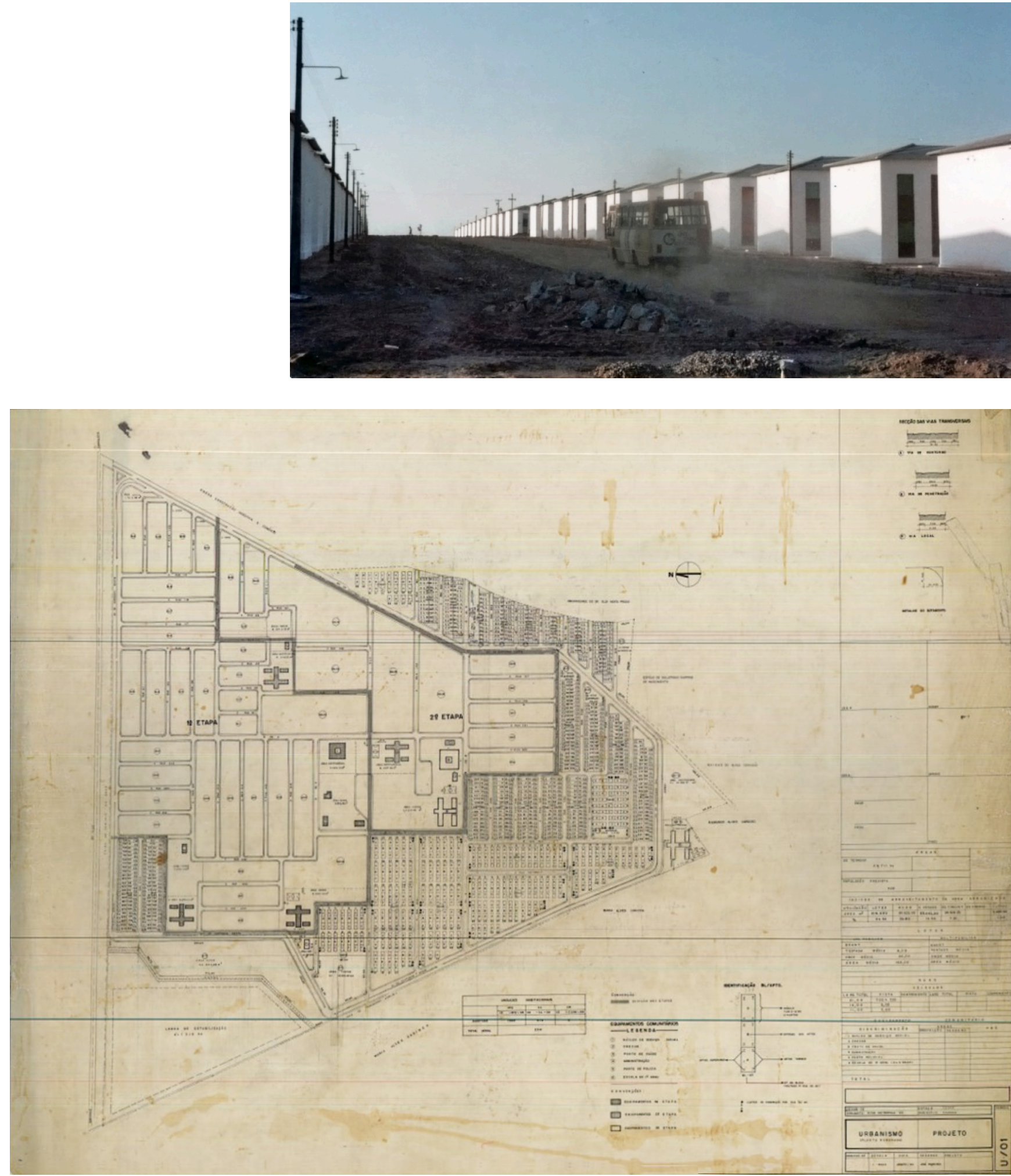

Figura 3 (topo): Unidades habitacionais do Conjunto Esperança em 1982. Fonte: Acervo de imagens da CAIXA Cultural.

Figura 4: Projeto do Conjunto Nova Metrópole, construído pelo BNH em Caucaia. Fonte: Acervo técnico da COHAB-CE. 
Figura 5: Mapa de localização dos conjuntos-bairros na Região Metropolitana de Fortaleza.Fonte: Elaboração própria sobre base do Observatório das Metrópoles / IPPUR / UFRJ.
Localizado a oeste de Fortaleza, no município de Caucaia, o Conjunto Habitacional Nova Metrópole foi entregue através de três etapas, sendo a primeira no ano de 1984 e a última em 1989. No total, o conjunto previa 5537 unidades habitacionais, distribuídas nas diferentes etapas. Assim como outros conjuntos da época o Nova Metrópole apresentava além das habitações, alguns equipamentos como praças, posto de saúde, serviço social e posto policial. Assim como o Esperança, divide-se em duas áreas com predominância do uso residencial e com características bem distintas definidas pela tipologia habitacional: uma parte composta por blocos residenciais multifamiliares de dois pavimentos e outra compreendida por unidades habitacionais térreas, unifamiliares e isoladas no lote. Diferencia-se daqueles pela predominância, territorial e numérica, das unidades habitacionais em blocos de apartamentos multifamiliares.

O Conjunto Ceará, inicialmente chamado Confiança (Castro, Guedes \& Britto, 1972), é o maior conjunto-bairro construído em Fortaleza. Foi implantado no setor sudoeste da cidade, no limite com Caucaia e em trecho próximo a outros grandes conjuntos, como o Araturi. Chamamos o Ceará de conjunto-bairro, mas na verdade, pelo porte que apresenta, ele está dividido em dois bairros oficialmente adotados pela Prefeitura de Fortaleza. Compreende uma área de aproximadamente 390 hectares e previa, segundo o projeto, abrigar uma população entre 70 mil e 80 mil habitantes. Foram construídas 8669 unidades habitacionais, entregues em quatro etapas no período entre os anos de 1977 e 1981. Estas unidades habitacionais foram construídas em lotes de 200 metros quadrados, possuindo variações tipológicas associadas ao número de dormitórios. Assim como o José Walter, também previa, em seu projeto, uma série de equipamentos sociais tais como: escolas, posto de saúde, correios, centro social, delegacia, centros comerciais, igreja e praças de esporte.

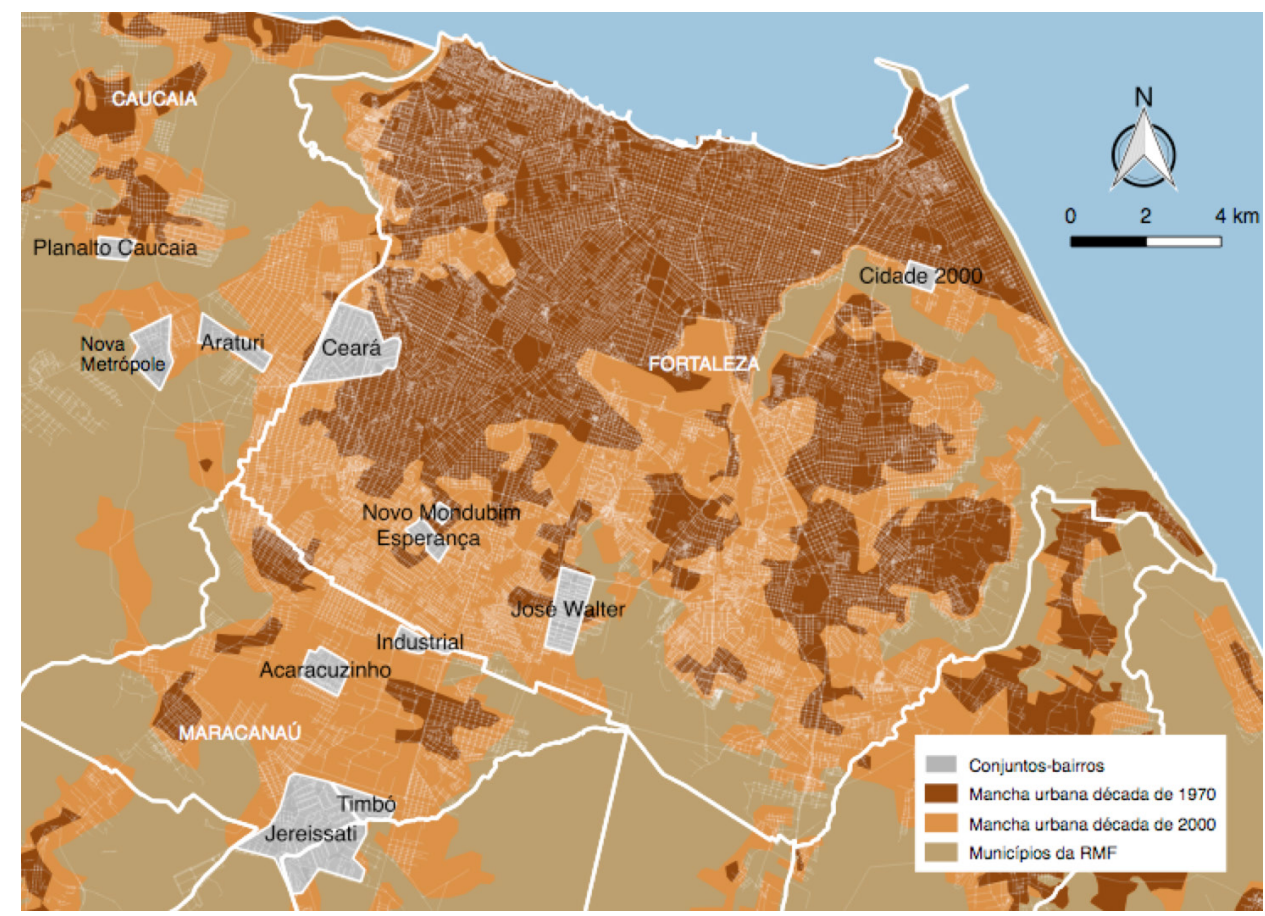




\section{Algumas notas conclusivas}

Mesmo se tratando de um contexto municipal específico, Fortaleza apresenta um caso paradigmático quanto ao processo de expansão do seu espaço intraurbano. Dentre vários fatores que explicam esse processo, a produção habitacional do BNH na capital cearense, através da construção dos aqui chamados conjuntos-bairros, expressa de maneira clara algumas questões relacionadas a tal processo: a localização periférica e a produção em massa dos empreendimentos habitacionais; e os programas de desfavelamento de áreas bem localizadas para relocação da população moradora destas favelas em conjuntos periféricos.

Ressalta-se ainda que tal expansão da periferia metropolitana, através da construção destes conjuntos-bairros, é muito mais uma decorrência da lógica da produção habitacional do que uma intencional e planejada integração socioespacial, política e econômica entre os municípios que integram a região metropolitana. Com efeito, a metrópole continua a concentrar a maior parte da população, do emprego e da renda, ainda que as diferenças intermunicipais tenham sido reduzidas ao longo do tempo.

A intervenção do Estado no setor habitacional contribuiu muito mais para dinamizar o mercado imobiliário de alta e média renda, do que para efetivamente resolver o problema da habitação popular. Os programas de desfavelamento e a construção de conjuntos habitacionais não conseguiram conter o crescimento das favelas, cuja população passa de cerca de 220 mil habitantes em 1970, para mais de 330 mil em 1981, enquanto o número de favelas aumenta de 73 para 268 no mesmo período (Gondim, 1987).

Tamanho é o problema habitacional em Fortaleza, apesar da dimensão das ações acima apresentadas, que a favelização passou a ser enfrentada através da urbanização e implantação de infraestrutura. Nos últimos anos, percebe-se a opção das ações governamentais na área de habitação direcionadas à urbanização de favelas e áreas de risco (Pequeno, 2002; Pequeno \& Aragão, 2009). Tem-se como tendência a concentração de investimentos visando a melhoria habitacional no espaço intraurbano já produzido, contribuindo para a retração de sua expansão. Dessa forma, decorre uma diferenciação do que havia sido produzido no passado, quando as intervenções governamentais, através da construção dos grandes conjuntos habitacionais, propiciaram a ocupação da periferia do espaço periférico metropolitano.

Apesar do elevado montante de recursos envolvidos no período de operação do SFH via BNH, a carência habitacional, representada pelo incremento da favelização e dos loteamentos precários, cresceu de maneira acentuada. A atuação daquele Banco esteve muito distante de enfrentar a magnitude dos problemas relativos à carência habitacional das camadas populares em virtude da lógica eminentemente empresarial que o constituía, em geral não comportando soluções subsidiadas e excluindo os segmentos de mais baixa renda do acesso aos financiamentos. De fato, em nenhum momento ao longo desse período de atuação mais efetiva do Estado na questão da moradia popular houve um real atendimento às demandas habitacionais das camadas de baixa renda, não se efetivando como política de Estado destinada a universalizar o direito à moradia. 


\section{Referências bibliográficas}

ACCIOLY, Vera Mamede. Estruturação urbana e mobilidade na Região Metropolitana de Fortaleza. In: PEQUENO, Renato (Org). Como anda Fortaleza. Coleção Conjuntura Urbana, Vol.5. Rio de Janeiro: Letra Capital/Observatório das Metrópoles, 2009.

BONDUKI, Nabil. Origens da habitação social no Brasil: arquitetura moderna, lei do inquilinato e difusão da casa própria. 6a. Edição. São Paulo: Estação Liberdade, 2013. 344p.

BRAGA, Elza Maria Franco; BARREIRA, Irlys Alencar Firmo (Org.). A Política da escassez: lutas urbanas e programas sociais governamentais. Fortaleza: Fundação Demócrito Rocha, 1991.

CASTRO, José Liberal de; GUEDES, Joaquim; BRITTO, Alfredo. Análise do programa de desfavelamento, do projeto de execução do Núcleo Confiança e da implementação de equipamentos de uso comunitário no Núcleo Habitacional Integrado do Mondubim. Fortaleza, 1972.

CEARÁ. Revisão da política habitacional para as populações de baixa renda. Governo do Estado do Ceará, Fundação Instituto de Planejamento do Ceará. Fortaleza: Iplance, 1978.

CETREDE. A expansão da periferia urbana de Fortaleza e seu efeito de segregação e deterioração da qualidade de vida da população. Monografia (Curso de Desenvolvimento Urbano e Regional) - Centro de Treinamento em Desenvolvimento Econômico e Regional, Fortaleza, 1981.

COMAS, Carlos. Eduardo Dias. O espaço da arbitrariedade: considerações sobre o conjunto habitacional BNH e o projeto da cidade brasileira. Brasília: Revista do serviço público, Escola Nacional de Administração Pública (ENAP), 1983. V. 111, n. 1, p. 21-28.

COSTA, Maria Clélia Lustosa da. Cidade 2000: expansão urbana e segregação espacial em Fortaleza. Dissertação (Mestrado em Geografia Humana) - Faculdade de Filosofia, Letras e Ciências Humanas, Universidade de São Paulo. São Paulo, 1988

COSTA, Maria Clélia Lustosa da (2005). Fortaleza: expansão urbana e organização do espaço. In: SILVA, José Bozarchiello da; CAVALCANTE, Tercia; DANTAS, Eustógio. Ceará: um novo olhar geográfico. Fortaleza, Edições Demócrito Rocha, 2005. p.51-100.

FORTALEZA. Plano de Desenvolvimento Integrado da Região Metropolitana de Fortaleza Plandirf. Fortaleza: Prefeitura Municipal de Fortaleza, 1972.

Programa integrado de desfavelamento de Fortaleza: estudo preliminar. Fortaleza, Prefeitura Municipal de Fortaleza, 1973.

GONDIM, Linda Maria Pontes. Fortaleza 1987: crescimento, opulência e miséria. Fortaleza, 1987. Universidade Federal do Ceará, Mestrado em Economia, Série Textos para Discussão, n.65.

JUCÁ, Gisafran Nazareno Mota. Verso e reverso do perfil urbano de Fortaleza (1945-1960). São Paulo: Anna Blume, 2003.

MARTINS, Maria de Fátima Almeida. Habitação popular na periferia de Fortaleza: o conjunto habitacional Jereissati, do espaço planejado ao espaço vivido. Dissertação (mestrado em Geografia Humana) - Faculdade de Filosofia, Letras e Ciências Humanas, Universidade de São Paulo. São Paulo, 1995.

MARICATO, Ermínia. Política habitacional no regime militar: do milagre brasileiro à crise econômica. Petrópolis: Vozes, 1987.

MÁXIMO, Rérisson. Moradia, arquitetura e cidade: mudanças e permanências na produção da habitação social no espaço urbano metropolitano de Fortaleza. Dissertação (mestrado em Arquitetura e Urbanismo) - Instituto de Arquitetura e Urbanismo, Universidade de São Paulo. São Carlos, 2012.

MESQUITA, Maria Elenise et al. COHAB: ontem, hoje e a lembrança. Fortaleza, Editora Gráfica Goldgraf, 2000. 
PEQUENO, Renato. Desenvolvimento e degradação do espaço intra-urbano de Fortaleza. Tese (doutorado em Arquitetura e Urbanismo) - Faculdade de Arquitetura e Urbanismo, Universidade de São Paulo. São Paulo, 2002.

PEQUENO, Renato; ARAGÃO, Thêmis. Dimensão habitacional da Região Metropolitana de Fortaleza. In: PEQUENO, Renato (Org). Como anda Fortaleza. Coleção Conjuntura Urbana, Observatório das Metrópoles, Vol.5. Rio de Janeiro: Letra Capital, 2009.

RUBANO, Lizete Maria. Cultura de projeto: um estudo das idéias e propostas para habitação coletiva. Tese (doutorado em em Arquitetura e Urbanismo) - Faculdade de Arquitetura e Urbanismo, Universidade de São Paulo. São Paulo, 2002.

VILLAÇA, Flávio. Espaço intra-urbano no Brasil. São Paulo, FAPESP / Studio Nobel, 2001. 